\title{
Fixed combination of bimatoprost and timolol in patients with primary open-angle glaucoma or ocular hypertension with inadequate IOP adjustment
}

\author{
This article was published in the following Dove Press journal: \\ Clinical Ophthalmology \\ 28 September 2010 \\ Number of times this article has been viewed
}

\author{
Gerrett Brief \\ Tobias Lammich ${ }^{2}$ \\ Edgar $\mathrm{Nagel}^{3}$ \\ Sabine Pfennigsdorf ${ }^{4}$ \\ Christoph W Spraul \\ Selwyn $\mathrm{Ho}^{6}$ \\ 'Facharzt für Augenheilkunde, \\ Dortmund, Germany; ${ }^{2}$ Neubrandenburg, \\ Germany; ${ }^{3}$ Augenarztpraxis \\ Rudolstadt, Germany; ${ }^{4}$ Polch, \\ Germany; ${ }^{5}$ Geiselhart, Ulm, Germany; \\ ${ }^{6}$ Allergan Europe, Marlow, UK
}

Correspondence: Gerrett Brief

Facharzt für Augenheilkunde, Kaubomstr7, 44388 Dortmund, Germany

Tel +4923I632929

Fax +49231631850

Email gerrett.brief@dgn.de
Objective: To assess the efficacy and tolerability of a fixed combination of bimatoprost and timolol (BTFC) in a large patient sample in a clinical setting.

Methods: In this multicenter, observational, noncontrolled, open-label study, patients ( $\mathrm{n}=1862)$ with primary open-angle glaucoma or ocular hypertension were treated with BTFC. Assessments were made at baseline, six weeks, and three months.

Results: Prior to starting BTFC, $92.3 \%$ of patients were taking other ocular hypotensive medications. In the overall group at three months, mean intraocular pressure was reduced from baseline $(21.7 \pm 4.5 \mathrm{mmHg}$ and $21.8 \pm 4.9 \mathrm{mmHg}$ for the right and left eye, respectively) to $16.1 \pm 3.0 \mathrm{mmHg}$ for each eye $(P<0.0001)$. The majority of patients $(92 \%)$ reported no adverse events. The most commonly reported adverse events (in $>1 \%$ of patients) were eye irritation, and ocular and conjunctival hyperemia. Adherence to treatment was generally better than $(35.4 \%)$ or the same as $(57.5 \%)$ with prior therapy. BTFC tolerability was rated as excellent or good by $92.3 \%$ of physicians and $85.8 \%$ of patients.

Conclusions: In a large group of patients with primary open-angle glaucoma or ocular hypertension, treatment with BTFC was associated with consistent reductions in IOP, improved adherence to treatment, and good tolerability.

Keywords: bimatoprost, timolol, intraocular pressure, fixed combination, glaucoma

\section{Introduction}

Glaucoma is the second most common cause of blindness in adults, both in Central Europe and worldwide. ${ }^{1}$ A significant risk factor associated with glaucoma is elevated intraocular pressure (IOP). ${ }^{2,3}$ The importance of IOP as a modifiable risk factor for visual field progression in glaucoma is well established. ${ }^{4-8}$ For example, in the Canadian Glaucoma Study, mean IOP at follow-up was significantly associated with visual field progression, with every $1 \mathrm{mmHg}$ increment in IOP increasing the risk of progression by $19 \% .{ }^{4}$ Other risk factors for glaucoma include increased age, optic disc and visual defects, corneal thickness, and myopia., ${ }^{2,3}$

Commonly prescribed glaucoma medicines may take the form of monotherapies, adjunctive combinations, or fixed combination treatments. In the long term, monotherapy provides insufficient IOP lowering in the majority of patients. ${ }^{9}$ However, the adjunctive use of several hypotensive medications also has potential disadvantages, such as an increased dosing frequency, which has been linked with poor compliance, ${ }^{9-11}$ 
the washout effect of multiple instillations, ${ }^{10}$ and the increased adverse event burden of multiple medications. ${ }^{12}$

Randomized clinical trials have shown that the fixed combination of bimatoprost and timolol (BTFC) is effective in reducing IOP. ${ }^{13,14}$ Bimatoprost is a prostamide which is thought to lower IOP largely by increasing uveoscleral outflow, whereas timolol blocks $\beta$-adrenergic receptors in the ciliary body, thus decreasing aqueous humor production. ${ }^{15}$ In a study comparing BTFC with its individual constituents in patients with glaucoma or ocular hypertension, BTFC caused a greater reduction in IOP than timolol or bimatoprost alone. ${ }^{13}$ The purpose of this observational study was to assess the IOP-lowering efficacy, tolerability, compliance, and therapeutic safety of BTFC in a large patient sample in a routine clinical setting.

\section{Methods}

\section{Study design}

This was a multicenter, observational, open-label, exploratory, noninterventional, nonblinded study conducted in 400 centers in Germany. The centers and physicians were selected by Allergan GmbH, Germany. Patients were followed over three visits, ie, a baseline visit and follow-up visits at six weeks and three months. Patients were treated with BTFC (Ganfort ${ }^{\circledR}$; Allergan Inc., Dublin, Ireland; $0.3 \mathrm{mg} / \mathrm{mL}$ bimatoprost, $5 \mathrm{mg} / \mathrm{mL}$ timolol) at a dose determined by their physician and guided by the summary of product characteristics within the clinical setting. Participation in the study did not influence the prescription of BTFC or any other drug. Data were gathered anonymously, in accordance with German law.

\section{Patients}

The study included patients with primary open-angle glaucoma or ocular hypertension, primarily those with insufficient IOP adjustment from previous $\beta$-blocker monotherapy.

\section{Measurements}

At the first visit, demographic and risk factor information (elevated IOP, family history of glaucoma, visual and optic disc defects), previous therapy, and IOP readings were recorded. The presence of optic cup and visual field defects was rated on a three-step scale (mild, moderate, and advanced). The reasons for changing therapy in patients who were receiving previous IOP-lowering therapy prior to BTFC treatment were recorded according to several categories, ie, insufficient IOP adjustment, appearance of glaucoma-related damage, progression of glaucoma-related damage, insufficient tolerability, lack of compliance, and other reasons. More than one reason could be recorded for each patient. Individual target IOP for right and left eyes was recorded.

The primary efficacy variable was the mean change in IOP from baseline to end of study at the third visit. IOP measurements were made for each eye three times (baseline, six weeks, three months) over the study period after switching to BTFC.

Other efficacy measures included physician-reported assessment of BTFC in terms of IOP reduction using a fourpoint scale, ie, excellent, good, moderate, and insufficient. Tolerability was assessed by questionnaires completed by both physicians and patients at the final examination using a four-point scale, ie, excellent, good, moderate, and bad. Patient compliance with BTFC was compared with previous therapy and rated by the physician as better, equal, or worse. All adverse events were recorded at the final visit as free-text entries using a questionnaire.

\section{Statistical analysis}

The planned sample size was 2000 patients from up to 400 ophthalmology centers; this patient number allowed for the detection of uncommon adverse events with an incidence of $<0.1 \%$ at least once ( $\alpha=0.05$, binomial distribution). Analyses were performed on the total sample unless otherwise stated. IOP was calculated as mean and standard deviation (SD). A two-sided paired-difference $t$-test was performed on the null hypothesis that IOP does not change after three months of study treatment. All statistics were performed using SAS ${ }^{\circledR}$ software (version 9.1.3; SAS Institute Inc., Cary, NC).

\section{Results}

The study included 1862 patients (57.4\% female, $42.6 \%$ male) with primary open-angle glaucoma or ocular hypertension (Table 1). Most (72.5\%) patients were $>60$ years old. Elevated IOP was the most commonly reported risk factor for glaucoma $(81 \%)$, with $10 \%$ reporting both high IOP and a family history. The mean time since first diagnosis of elevated IOP was 7.7 years. Most patients had at least mild visual defects and optic disc defects at the baseline visit. The mean target IOP (mean of all individually identified target $\mathrm{IOP} \pm \mathrm{SD}$ ) for the population was $16.2 \pm 2.3 \mathrm{mmHg}$ in both the right and left eyes.

\section{Prior therapy}

Prior to switching to BTFC, 92.3\% of patients $(n=1719)$ were recorded as taking other medications (Table 2). The remaining $143(7.7 \%)$ patients either had not been receiving 
Table I Patient demographics at baseline $(n=1862)$

\begin{tabular}{|c|c|c|c|}
\hline & $\begin{array}{l}\text { Mean } \pm \text { SD } \\
\text { (range) }\end{array}$ & $\mathbf{n}$ & $\%$ \\
\hline Age (years) & $\begin{array}{l}67.1 \pm 11.8 \\
(6-95)\end{array}$ & $|8| 1$ & \\
\hline Male & & 793 & 42.6 \\
\hline Female & & 1069 & 57.4 \\
\hline $\begin{array}{l}\text { Elevated IOP first diagnosed } \\
\text { previous to trial (years) }\end{array}$ & $\begin{array}{l}7.7 \pm 6.2 \\
(I-7 I)\end{array}$ & 1300 & \\
\hline \multicolumn{4}{|l|}{ Corneal thickness $(\mu \mathrm{m})$} \\
\hline Right eye & $\begin{array}{l}550.5 \pm 69.8 \\
(400-1600)\end{array}$ & 601 & \\
\hline Left eye & $\begin{array}{l}552.4 \pm 76.1 \\
(400-1730)\end{array}$ & 603 & \\
\hline \multicolumn{4}{|l|}{ Risk factors } \\
\hline High IOP & & 1509 & 81.0 \\
\hline Family history of glaucoma & & 312 & 16.8 \\
\hline \multicolumn{4}{|l|}{ Visual field defects } \\
\hline Mild & & $1454 *$ & 57.0 \\
\hline Moderate & & $718^{*}$ & 28.0 \\
\hline Advanced & & $381 *$ & 15.0 \\
\hline Missing information & & $|17| *$ & $\mathrm{n} / \mathrm{a}$ \\
\hline \multicolumn{4}{|l|}{ Optic disc defects } \\
\hline Mild & & $1235^{*}$ & 45.0 \\
\hline Moderate & & $920 *$ & 34.0 \\
\hline Advanced & & $566^{*}$ & 21.0 \\
\hline Missing information & & $1003 *$ & $\mathrm{n} / \mathrm{a}$ \\
\hline
\end{tabular}

Note: *Refers to number of eyes; $n=3724$ eyes.

Abbreviations: IOP, intraocular pressure; $\mathrm{n} / \mathrm{a}$, not available; SD, standard deviation.

prior IOP-lowering therapy or had no available information regarding previous therapy. Prior therapy was timolol-based in the majority of patients (57.5\%, either monotherapy or in combination with other therapies). Three patients $(0.2 \%)$ had previously been using bimatoprost and timolol as an adjunctive combination. Of the 1719 patients previously taking other medications, 1387 (81\%) were taking monotherapies, 292 (17\%) were taking two adjunctive therapies, and $40(2 \%)$ were taking three or more adjunctive therapies. Reasons for the change in medication were insufficient IOP lowering (86.3\%), progression of glaucoma-related damage (25.6\%), insufficient tolerability (13.1\%), lack of compliance (11.8\%), appearance of glaucoma-related damage (10.4\%), and other reasons $(2.3 \%)$, with some patients changing for more than one reason.

\section{BTFC therapy}

At each visit, the dosage of BTFC was reassessed and prescribed as either none, once, twice or more times a day for each eye. The most common dose, used by $93.8 \%$ of patients, was once a day for each eye, as would be expected, given that this agent is licensed for once-daily dosing.
Table 2 Prior medications taken by $>1 \%$ of patients, among those whose prior therapy was documented $(n=1719)^{*}$

\begin{tabular}{|c|c|c|c|}
\hline Medication & $\mathbf{n}$ & $\%$ & Active agent(s) \\
\hline Xalatan $^{\circledR}$ & 286 & 16.6 & Latanoprost $(0.005 \%)$ \\
\hline Tim $^{\circledR}$-Ophtal ${ }^{\circledR}$ & 195 & 11.3 & Timolol $(0.1 \%, 0.25 \%, 0.5 \%)$ \\
\hline Timolol & 185 & 10.8 & Timolol $(0.1 \%, 0.25 \%, 0.5 \%)$ \\
\hline Cosopt $^{\circledR}$ & 175 & 10.2 & Timolol (0.5\%), dorzolamide $(0.2 \%)$ \\
\hline Lumigan $^{\circledR}$ & 146 & 8.5 & Bimatoprost $(0.03 \%)$ \\
\hline Azopt ${ }^{\circledR}$ & 144 & 8.4 & Brinzolamide (I\%) \\
\hline Travatan $^{\circledR}$ & 135 & 7.9 & Travoprost $(0.004 \%)$ \\
\hline Xalacom $^{\circledR}$ & 125 & 7.3 & Timolol (0.5\%), latanoprost $(0.005 \%)$ \\
\hline Trusopt $^{\circledR}$ & 74 & 4.3 & Dorzolamide $(2 \%)$ \\
\hline Alphagan ${ }^{\circledR}$ & 71 & 4.1 & Brimonidine $(0.1 \%, 0.15 \%)$ \\
\hline DuoTrav ${ }^{\circledR}$ & 70 & 4.1 & Timolol $(0.5 \%)$, travoprost $(0.004 \%)$ \\
\hline Betamann $^{\circledR}$ & 59 & 3.4 & Metipranolol $(0.1 \%, 0.3 \%, 0.6 \%)$ \\
\hline Timomann $^{\circledR}$ & 54 & 3.1 & Timolol $(0.1 \%, 0.25 \%, 0.5 \%)$ \\
\hline Combigan $^{\circledR}$ & 47 & 2.7 & Timolol $(0.5 \%)$, brimonidine $(0.2 \%)$ \\
\hline Arutimol ${ }^{\circledast /} /$-uno & 41 & 2.4 & Timolol $(0.25 \%, 0.5 \%)$ \\
\hline NyoGel ${ }^{\circledR}$ & 31 & 1.8 & Timolol (0.1\%) \\
\hline Timo-comod $^{\circledR}$ & 30 & 1.7 & Timolol $(0.25 \%, 0.5 \%)$ \\
\hline Clonid-Ophta ${ }^{\circledR}$ & 28 & 1.6 & Clonidine $(0.063 \%, 0.125 \%)$ \\
\hline Vistagan ${ }^{\circledR}$ & 25 & 1.5 & Levobunolol $(0.1 \%, 0.25 \%, 0.5 \%)$ \\
\hline Timohexa $^{\circledR}$ & 21 & 1.2 & Timolol $(0.1 \%, 0.25 \%, 0.5 \%)$ \\
\hline
\end{tabular}

Note: *Individual patients could have received more than one category of intraocular pressure-lowering medication.

At the baseline visit, $88.5 \%$ of patients were using BTFC alone, $10.3 \%$ were using BTFC with additional medication, and data were unavailable for $1.2 \%$. At the second visit (mean duration of BTFC treatment $6.7 \pm 5.3$ weeks), $84.6 \%$ of patients were using BTFC as single therapy, $12.0 \%$ were using BTFC with additional medication, and data were missing for $3.4 \%$. At the final visit (mean duration of BTFC treatment $16.4 \pm 8.1$ weeks), $80.2 \%$ of patients were using BTFC as single therapy, $13.4 \%$ were taking additional medication, and data were unavailable for $6.3 \%$.

\section{Effect on IOP}

Baseline IOP (mean \pm SD) in the total group was $21.7 \pm 4.5 \mathrm{mmHg}(\mathrm{n}=1850)$ and $21.8 \pm 4.9 \mathrm{mmHg}$ $(\mathrm{n}=1853)$ for the right and left eyes, respectively (Figure 1). In the total group at six weeks, mean IOP was reduced to $16.6 \pm 3.3 \mathrm{mmHg}$ for both right and left eyes (Figure 1). At three months, mean IOP was further reduced to $16.1 \pm 3.0 \mathrm{mmHg}$ for both right and left eyes (Figure 1, $P<0.0001$ by $t$-test).

Mean IOP was also calculated for patients with complete data $(\mathrm{n}=1775$ patients with right eye data, $\mathrm{n}=1778$ patients with left eye data). Mean baseline IOP was $21.8 \pm 4.5 \mathrm{mmHg}$ in the right eye and $21.8 \pm 4.8 \mathrm{mmHg}$ in the left eye. After three months, mean IOP was $16.1 \pm 3.0 \mathrm{mmHg}$ in both the right and left eyes for this subset of patients with complete data. 


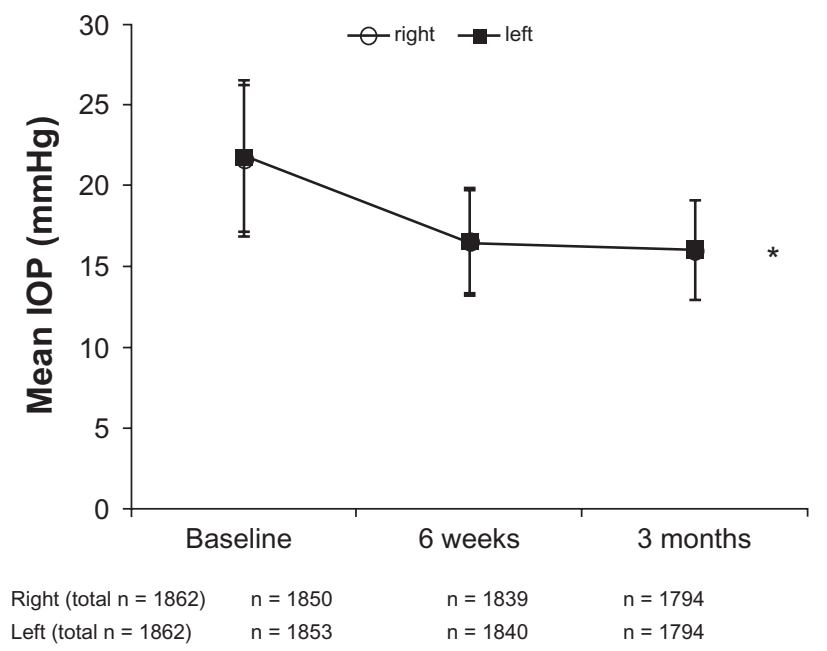

Figure I Mean IOP $( \pm S D)$ at baseline, six weeks, and three months, for right and left eyes in the total population.

Note: $* P<0.0001$ compared with baseline.

Abbreviation: IOP, intraocular pressure.

Over half of the total population achieved an IOP of $\leq 16 \mathrm{mmHg}$ by the end of the study at three months; $56.2 \%$ of right eyes and $54.8 \%$ of left eyes achieved an IOP $\leq 16 \mathrm{mmHg}$ (Figure 2). In over a quarter of eyes studied (left and right), IOP was further reduced to $\leq 14 \mathrm{mmHg}$ by three months (Figure 2). Physicians rated overall efficacy of BTFC on IOP reduction as "excellent" or "good" in $89.2 \%$ of the overall group.

\section{Tolerability and safety}

Few adverse events were associated with the use of BTFC (7.7\%), and most patients (92\%) reported no adverse events. The most commonly reported adverse events (in $>1 \%$ of patients) were eye irritation (2.2\%), ocular hyperemia (1.6\%),

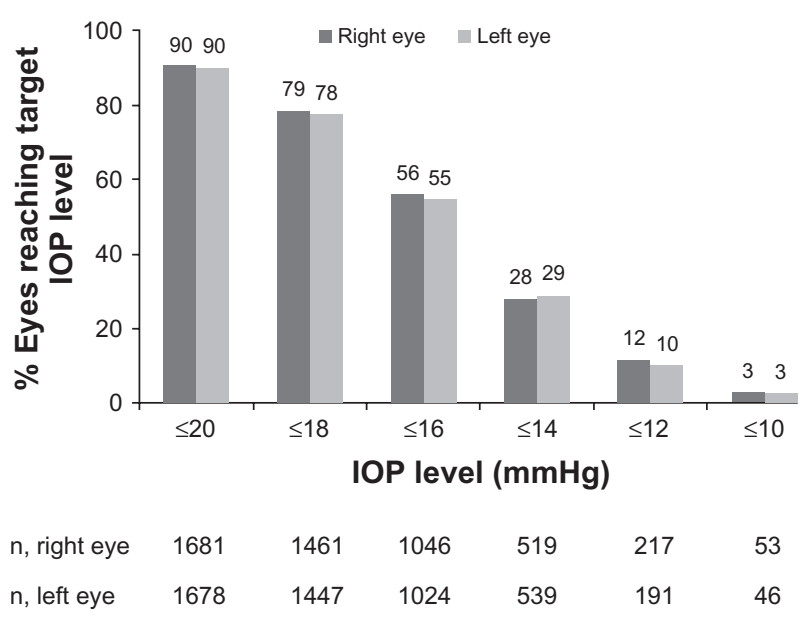

Figure 2 Percentage of right and left eyes achieving various IOP targets at three months.

Abbreviation: IOP, intraocular pressure. and conjunctival hyperemia (1.5\%). The tolerability of BTFC was rated as "excellent" or "good" by $92.3 \%$ of physicians and $85.8 \%$ of patients at three months. Compliance with treatment, as rated by the physician, was rated as better than (35.4\%) or the same as (57.5\%) that with previous therapy. Continuation of BTFC therapy beyond the end of the study was $82.9 \%$.

\section{Discussion}

In this German observational study reflecting clinical practice conditions, a large group of patients with primary open-angle glaucoma and ocular hypertension achieved further IOP reductions after switching therapy to BTFC. The change in IOP over the three-month observation period was highly significant $(P<0.0001$ by $t$-test). Most patients were switched to BTFC because of insufficient IOP lowering with their previous therapy. BTFC treatment was also associated with a low incidence of conjunctival hyperemia (1.5\%), good tolerability, and improved compliance compared with prior treatment.

In a double-masked, randomized study of 445 patients with glaucoma or ocular hypertension, a significantly lower incidence of conjunctival hyperemia was observed with the fixed combination of BTFC (8.5\%) versus the nonfixed combination (12.5\%) or single agent bimatoprost (18.9\%). ${ }^{14}$ A further study in 53 patients with glaucoma showed an improvement in hyperemia in $69 \%$ of patients switching from prior combination treatment to BTFC. ${ }^{16}$

Prior to switching to BTFC, patients in this study were taking a variety of therapies, including monotherapies and combined treatments, with the majority receiving timolol (57.5\%) or latanoprost (23.8\%). There are few published data regarding switching from a prior therapy to BTFC, but some smaller studies have shown significant reductions in IOP after switching to BTFC in patients whose IOP was inadequately controlled on previous therapies. ${ }^{16-18} \mathrm{An}$ observational study of 606 patients switched to BTFC from monotherapy (66.8\%), nonfixed combinations (17.2\%), and other fixed combinations (16.0\%) showed additional IOP reductions versus baseline. Furthermore, patients who had previously received $\beta$-blocker or prostaglandin analog treatment achieved an additional $25.8 \%$ or $22.6 \%$ decrease in IOP from baseline, respectively, after switching to BTFC treatment. ${ }^{18}$ After three months of BTFC treatment, $85 \%$ of all eyes achieved an IOP of $\leq 18 \mathrm{mmHg}$, which is similar to the findings in the current study.

Another study of 102 patients who switched to BTFC following inadequate treatment with monotherapy, or combination or fixed combination treatments also showed a decrease 
in mean IOP from baseline after two months. ${ }^{17}$ The reasons for the greater IOP lowering achieved when patients switch from previous therapy to BTFC may relate to improved compliance resulting from once-daily administration. ${ }^{11}$

This was an open-label observational study including many centers. Such a study has inherent limitations, which must be acknowledged. For instance, the noninterventional nature of the study means that there could be no washout period between the earlier prior medications and the switch to BTFC. The design is also essentially uncontrolled, making interpretation more difficult. However, the study captures important information regarding the use of fixed combinations in everyday life, and the results confirm that BTFC offers good efficacy and tolerability to patients with primary open-angle glaucoma or ocular hypertension with insufficient IOP control on previous therapy. These findings should be considered alongside results from well controlled, randomized clinical trials to guide the use of IOP-lowering therapy in clinical practice.

\section{Conclusion}

In this observational study, three months of BTFC treatment resulted in significant IOP reductions in a large group of patients in a German clinical setting, where most patients were previously insufficiently controlled on other hypotensive agents. BTFC was well tolerated and associated with a low rate of adverse events, a high level of both patient and physician reported satisfaction, and good adherence to treatment.

\section{Disclosure}

Allergan Ltd funded this study and provided the services of Darwin Healthcare Communications for editorial support.

\section{References}

1. Resnikoff S, Pascolini D, Etya'ale D, et al. Global data on visual impairment in the year 2002. Bull World Health Organ. 2004;82:844-851.

2. Gordon MO, Beiser JA, Brandt JD, et al. The Ocular Hypertension Treatment Study: Baseline factors that predict the onset of primary open-angle glaucoma. Arch Ophthalmol. 2002;120:714-720.

3. Burr JM, Mowatt G, Hernandez R, et al. The clinical effectiveness and cost-effectiveness of screening for open angle glaucoma: A systematic review and economic evaluation. Health Technol Assess. 2007;11(41): iii-iv, ix-x, 1-190.

Clinical Ophthalmology

\section{Publish your work in this journal}

Clinical Ophthalmology is an international, peer-reviewed journal covering all subspecialties within ophthalmology. Key topics include: Optometry; Visual science; Pharmacology and drug therapy in eye diseases; Basic Sciences; Primary and Secondary eye care; Patient Safety and Quality of Care Improvements. This journal is indexed on
4. Chauhan BC, Mikelberg FS, Balaszi AG, LeBlanc RP, Lesk MR, Trope GE. Canadian Glaucoma Study: Risk factors for the progression of open-angle glaucoma. Arch Ophthalmol. 2008;126:1030-1036.

5. Collaborative Normal-Tension Glaucoma Study Group. Comparison of glaucomatous progression between untreated patients with normaltension glaucoma and patients with therapeutically reduced intraocular pressures. Am J Ophthalmol. 1998;126:487-497.

6. Heijl A, Leske MC, Bengtsson B, Hyman L, Bengtsson B, Hussein M. Reduction of intraocular pressure and glaucoma progression: Results from the Early Manifest Glaucoma Trial. Arch Ophthalmol. 2002;120: $1268-1279$.

7. Kass MA, Heuer DK, Higginbotham EJ, et al. The Ocular Hypertension Treatment Study: A randomized trial determines that topical ocular hypotensive medication delays or prevents the onset of primary openangle glaucoma. Arch Ophthalmol. 2002;120:701-713.

8. Lichter PR, Musch DC, Gillespie BW, et al. Interim clinical outcomes in the Collaborative Initial Glaucoma Treatment Study comparing initial treatment randomized to medications or surgery. Ophthalmology. 2001; 108:1943-1953.

9. European Glaucoma Society. Terminology and Guidelines for Glaucoma. 3rd ed. Savona, Italy: Editrice Dogma; 2008.

10. Chrai SS, Makoid MC, Eriksen SP, Robinson JR. Drop size and initial dosing frequency problems of topically applied ophthalmic drugs. J Pharm Sci. 1974;63:333-338.

11. Patel SC, Spaeth GL. Compliance in patients prescribed eyedrops for glaucoma. Ophthalmic Surg. 1995;26:233-236.

12. Dunker S, Schmucker A, Maier H. Tolerability, quality of life, and persistency of use in patients with glaucoma who are switched to the fixed combination of latanoprost and timolol. Adv Ther. 2007;24: 376-386.

13. Brandt JD, Cantor LB, Katz LJ, Batoosingh AL, Chou C, Bossowska I. Bimatoprost/timolol fixed combination: A 3-month double-masked, randomized parallel comparison to its individual components in patients with glaucoma or ocular hypertension. J Glaucoma. 2008;17: 211-216.

14. Hommer A. A double-masked, randomized, parallel comparison of a fixed combination of bimatoprost $0.03 \% /$ timolol $0.5 \%$ with non-fixed combination use in patients with glaucoma or ocular hypertension. Eur J Ophthalmol. 2007;17:53-62.

15. Lim KS, Nau CB, O’Byrne MM, et al. Mechanism of action of bimatoprost, latanoprost, and travoprost in healthy subjects. A crossover study. Ophthalmology. 2008;115:790-795.

16. Skorkovska K. Comparison of intraocular pressure lowering efficacy of bimatoprost/timolol fixed combination and other glaucoma medications in the treatment of glaucoma. Cesk Slov Oftalmol. 2008;64:144-148. Czech.

17. Zafar A. A switch to bimatoprost/timolol fixed combination resulted in improved IOP reduction in patients with POAG, regardless of previous IOP-lowering therapy. Presented at: World Glaucoma Congress. Boston, MA: July 8-11, 2009.

18. Feuerhake C, Buchholz P, Kimmich F. Efficacy, tolerability and safety of the fixed combination of bimatoprost $0.03 \%$ and timolol $0.5 \%$ in a broad patient population: Multicenter, open-label observational study. Curr Med Res Opin. 2009;25:1037-1043.

PubMed Central and CAS, and is the official journal of The Society of Clinical Ophthalmology (SCO). The manuscript management system is completely online and includes a very quick and fair peer-review system, which is all easy to use. Visit http://www.dovepress.com/ testimonials.php to read real quotes from published authors. 